\title{
The Effect of Detergents on the Appearance of Automotive Clearcoat Systems Studied in an Outdoor Weathering Test
}

\author{
Mohammad S. Alsoufi ${ }^{*}$, Tahani M. Bawazeer ${ }^{2}$, Mohammed W. Alhazmi ${ }^{1}$, Sufyan Azam ${ }^{1}$ \\ ${ }^{1}$ Department of Mechanical Engineering, College of Engineering and Islamic Architecture, \\ Umm Al-Qura University, Makkah, KSA \\ ${ }^{2}$ Chemistry Department, Faculty of Applied Science, Umm Al-Qura University, Makkah, KSA \\ Email: *mssoufi@uqu.edu.sa
}

How to cite this paper: Alsoufi, M.S., Bawazeer, T.M., Alhazmi, M.W. and Azam, S. (2017) The Effect of Detergents on the Appearance of Automotive Clearcoat Systems Studied in an Outdoor Weathering Test. Materials Sciences and Applications, 8, 521-536.

https://doi.org/10.4236/msa.2017.87036

Received: June 1, 2017

Accepted: June 30, 2017

Published: July 3, 2017

Copyright $\odot 2017$ by authors and Scientific Research Publishing Inc. This work is licensed under the Creative Commons Attribution International License (CC BY 4.0).

http://creativecommons.org/licenses/by/4.0/

c) (i) Open Access

\begin{abstract}
The ability to predict the weathering performance of the clearcoat system over a short period of time is essential for the design and development of coating production. Thus, the primary objective of the present study is to investigate whether it is possible to predict the weathering performance of an automotive paint system through determination of surface roughness, $R_{\mathrm{a}}$, and microhardness before and after various weathering exposure times $(0,24,168,336$, 504,672 hours) and when employing two different detergent materials (house-use detergent and car wash detergent). The data were analysed using a pair-sample $t$-Test, with 0.05 level of significance. It was found that the total net of degradation in the clearcoat level during the first 24 hours was $R_{\mathrm{a}} \approx 30.3$ $\mathrm{nm}$ (for surface roughness) and $1.358 \mathrm{HV}$ (for the $\mu$-hardness) when using the house-use detergent. In contrast, it was found to be $R_{\mathrm{a}} \approx 4.6 \mathrm{~nm}$ (for surface roughness) and $1.133 \mathrm{HV}$ (for $\mu$-hardness) when using the car wash detergent. Also, increased time of weathering (up to 672 hours) increases the $R_{\mathrm{a}}$ and $\mu$-hardness values. It can therefore be concluded that the effect of house-use detergent was more severe than that of car wash detergent on the clearcoat system.
\end{abstract}

\section{Keywords}

Automotive, Clearcoat, Surface Roughness, Micro-Hardness

\section{Introduction}

In general, surfaces are not perfect [1]. Coatings, like all other engineering materials, will begin to degrade with time when placed in outdoor situations. Their degradation behaviour is due to the effect of various environmental conditions 
placed upon the coating system [2]. So, since the large scale introduction of clearcoat/basecoat (CC/BC) systems in the 1980's to the luxury vehicle production lines, their use has increased dramatically to the point where they are used on all vehicles today [3]. The appearance of a painted car body is undoubtedly highly significant for clients. This does not only seem to be a detrimental property but also its retention during the serving life is of great importance [4]. Automotive paint systems are typically comprised of up to five different layers of paint, as shown in Figure 1. The total film thickness of the automotive paint system is between 90 to $140 \mu \mathrm{m}$ where each layer serves a specific purpose [5]. Typically, a crystalline layer of metal phosphate is applied to galvanized steel to provide corrosion protection. Next, an organic coating containing corrosion inhibitors is electro-deposited (E-coat or ED-coat, $\sim 17-22 \mu \mathrm{m}$ ) over the phosphate crystal surface and cured to provide additional corrosion protection. The E-coat layer is then coated with a pigmented primer $(\sim 30-50 \mu \mathrm{m})$ to improve basecoat adhesion and also to shield the underlying E-coat from light. After the primer is cured, a pigmented basecoat $(\sim 10-20 \mu \mathrm{m})$ to provide color and a clearcoat $(\sim 30$ $50 \mu \mathrm{m})$ to provide gloss are applied over the primer and are themselves cured [6]. The final layer is expected to be responsible for outdoor weathering resistance [7]. So, the protection strategies against outdoor weathering conditions are usually implemented in the final layer. This therefore indicates that, the outdoor weathering conditions are considered as the most significant criterion for ranking the repeatability performances of clearcoat automotive paint systems.

Outdoor weathering conditions can severely affect the long-term aesthetic appeal of a car [8] whereas indoor conditions can less seriously affect it [9]. Over the last few years, the influence of different environmental factors such as sunlight, relative humidity and acid rain on the surface roughness, $R_{\mathrm{a}}$, of the automotive body has been comprehensively investigated [10] [11] [12]. Each of

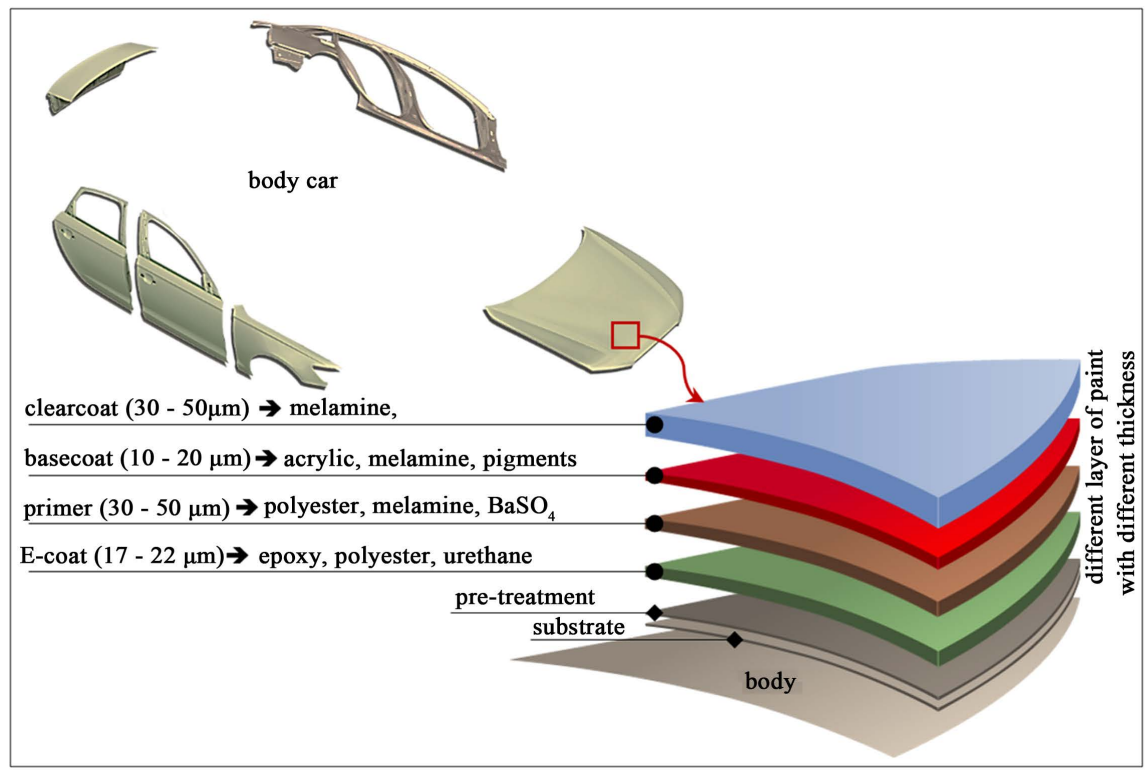

Figure 1. Typical automotive paint system. 
these factors plays a greater or lesser role depending on both the coating and the particular geographic location in which a layer is exposed. In these studies, the degradation effects of biological materials such as bird droppings and raw eggs have also been paid attention to recently [13] [14] [15]. Weathering, which causes an alteration in the chemical structure of a clearcoat [16] [17] [18] [19] [20], affects various aspects of it such as its physical [21], mechanical [11] [22] [23] [24] [25] and electromechanical properties [26]. In other words, the weathering performance anddurability of a clearcoat system indirectly reflects its mechanical and chemical stability and may cause that clearcoat to become vulnerable and fail as a result of hydrolysis, light, heat, moisture and photochemical degradations [27]. Due to the significant role of the clearcoat on the outdoor weathering and mechanical properties of the automotive coatings, the present study is a further attempt to investigate the effects of different detergents (house-use detergent and car wash detergent) on the appearance of automotive clearcoat systems in an outdoor weathering test. It seems clear that assessment of the weathering performance of the clearcoat is very significant. For the purposes of this assessment, the clearcoat layers were exposed to weathering condition. After that, the changes in morphology and chemistry of clearcoat layer were studied by assessing surface roughness, micro-hardness and scanning electronic microscopy (SEM).

\section{Experimental Method}

\subsection{Materials Selection and Preparations}

The substrate used throughout the experiments was a white-coloured painted automotive, from the Toyota Company, KSA, model 2016. Around 74 samples with identical dimensions' length of $30 \times 30 \times 0.85 \mathrm{~mm}$ were studied in this investigation. Abrasive waterjet cutting technology (from TecnoCut waterjet cutting systems) was used to excise sections of similar shape from the front of the painted automotive body surface, as shown in Figure 2. Details of the abrasive waterjet method have been reported elsewhere [28] [29]. Ideally, all samples were cleaned ultrasonically before starting the experiments. This was carried out to remove any contaminants, such as dust, grease, or any other soluble organic particles so that there would be no adverse effect on the results due to their presence.

In order to perform the experiment, the surface roughness and micro-hardness were measured in an air-conditioned room with an ambient temperature of $20^{\circ} \mathrm{C} \pm 1{ }^{\circ} \mathrm{C}$ and a relative humidity of $40 \% \pm 5 \% \mathrm{RH}$. The different detergents (car wash detergent or house-use detergent) were then applied using a stylus-typ Taly-Surf (Taylor Hobson Precision, Inc., UK) and Vickers indentation microhardness (Micro-hardness, Zwick Roell Indentec ZHV1-AFC, Germany).

After that, the sample was washed with either car wash detergent or house-use detergent as shown in Figure 3. Each sample was individually immersed in the detergent for 5 minutes' exposure time. After each cycle, all samples were rinsed with tap water and stored in outdoor environmental conditions. The coating 


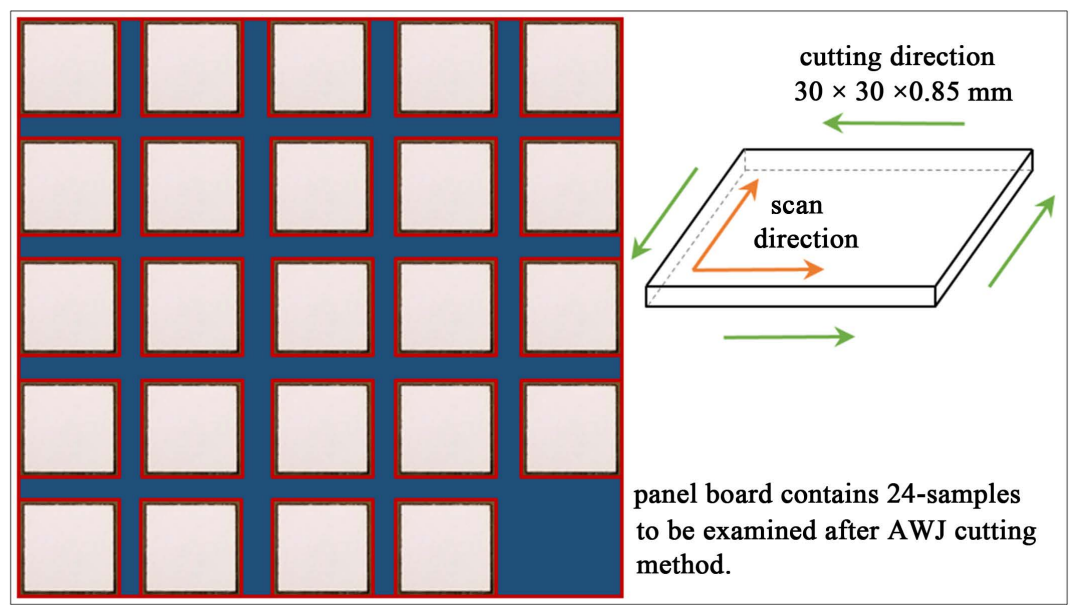

Figure 2. Samples with identical dimensions after AWJ cutting method.

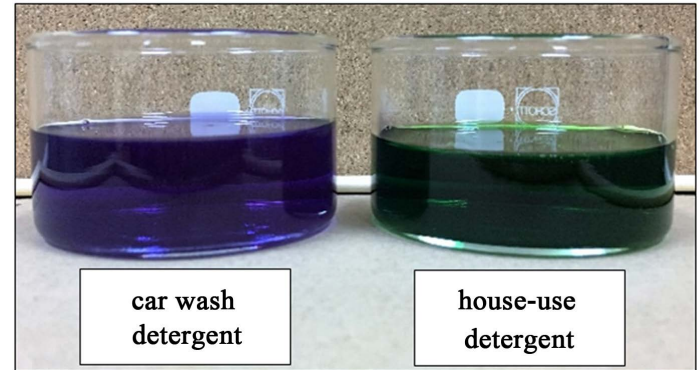

Figure 3. Car wash and house-use detergents.

samples were subjected to differing weathering exposure times $(0,24,168,336$, 504,672 hours) along with the two different detergent materials (house-use detergent and car wash detergent). The outdoor weathering tests were carried out in Makkah, a dry place with high temperature. The temperature $\left({ }^{\circ} \mathrm{C}\right)$ and relative humidity $(\% \mathrm{RH})$ were monitored and recorded each time the samples were collected

Finally, after various exposure times, all samples were measured in an airconditioned room, with an ambient temperature of $20^{\circ} \mathrm{C} \pm 1{ }^{\circ} \mathrm{C}$ and a relative humidity of $40 \% \pm 5 \%$ RH using a contact-type surface roughness and microhardness test.

\subsection{Testing Procedures}

The effects of the two different detergents (car wash detergent and house-use detergent) on the appearance of automotive paint systems were studied in an outdoor weathering test. The initial phase investigated the degradation during the first 24 hours and the later phase investigated subsequent degradation $(0,24$, $168,336,504,672$ hours). All the tests took place in weathering environments which imposed different kinds of degradations (e.g., temperature, humidity and so on) on a clearcoat automotive body surface during the investigation, see Figure 4. Temperature and relative humidity were measured (Mastercool ${ }^{\oplus}, 52232$ Temperature-Humidity Meter) during each experiment as shown in Figure 5. 


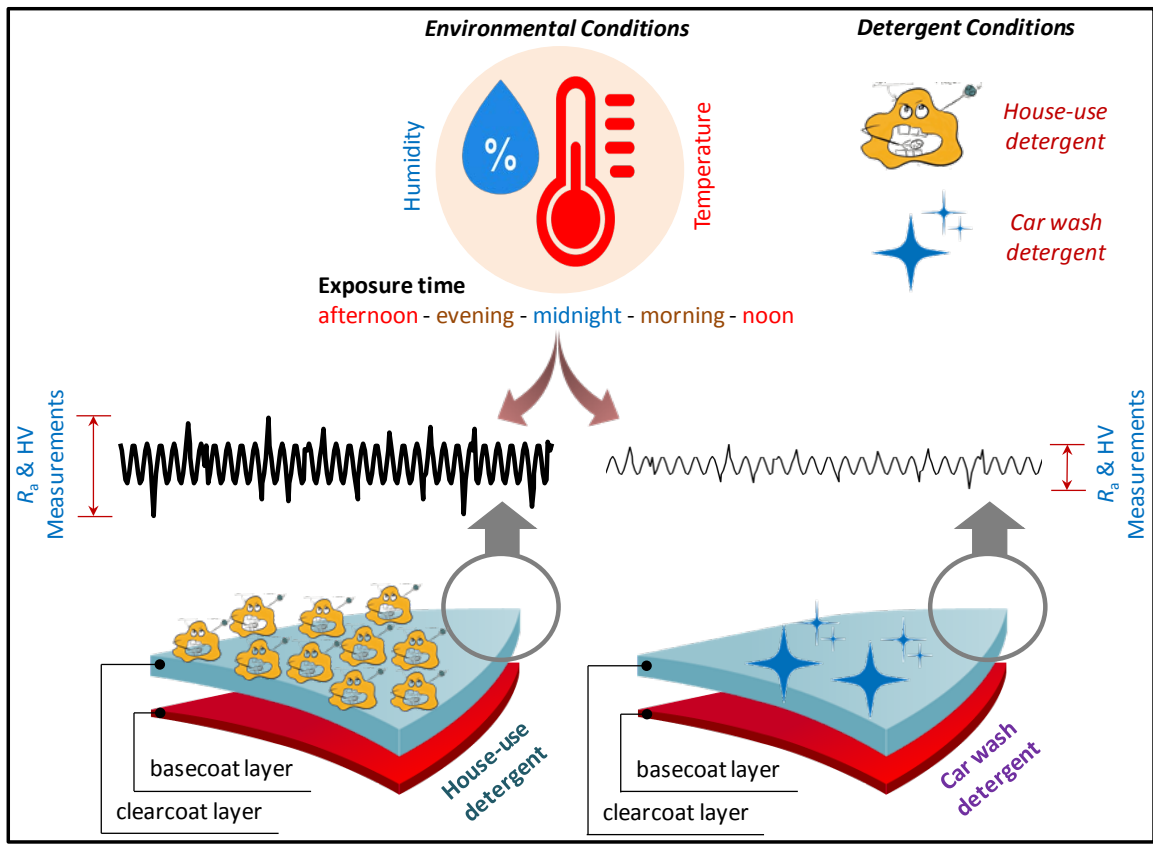

Figure 4. Surface profile behaviour under different conditions.

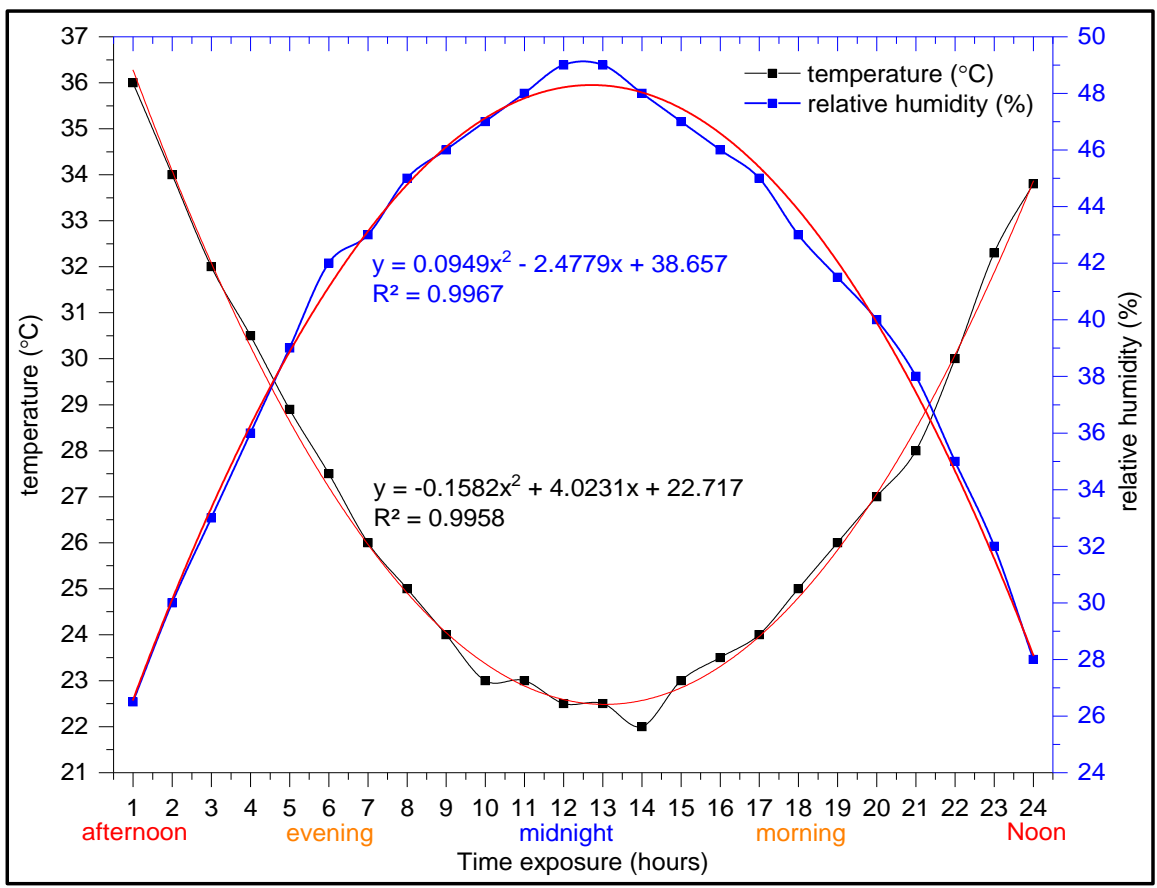

Figure 5. Temperature vs. relative humidity during the 24 hours of the experiment.

These can be particularly important factors when comparing the weathering behavior of a series of different time exposures vs. the temperature. Objects painted darker colours will typically be hotter than lighter objects. This temperature difference can lead a coating's degradation rate to be significantly colordependent. As a guide, the temperature of a series of steel panels painted with different colours of automotive topcoats (CC/BC) is shown in Figure 6. Thus, based on the data available in [2], it can be said that the white-painted colour is 


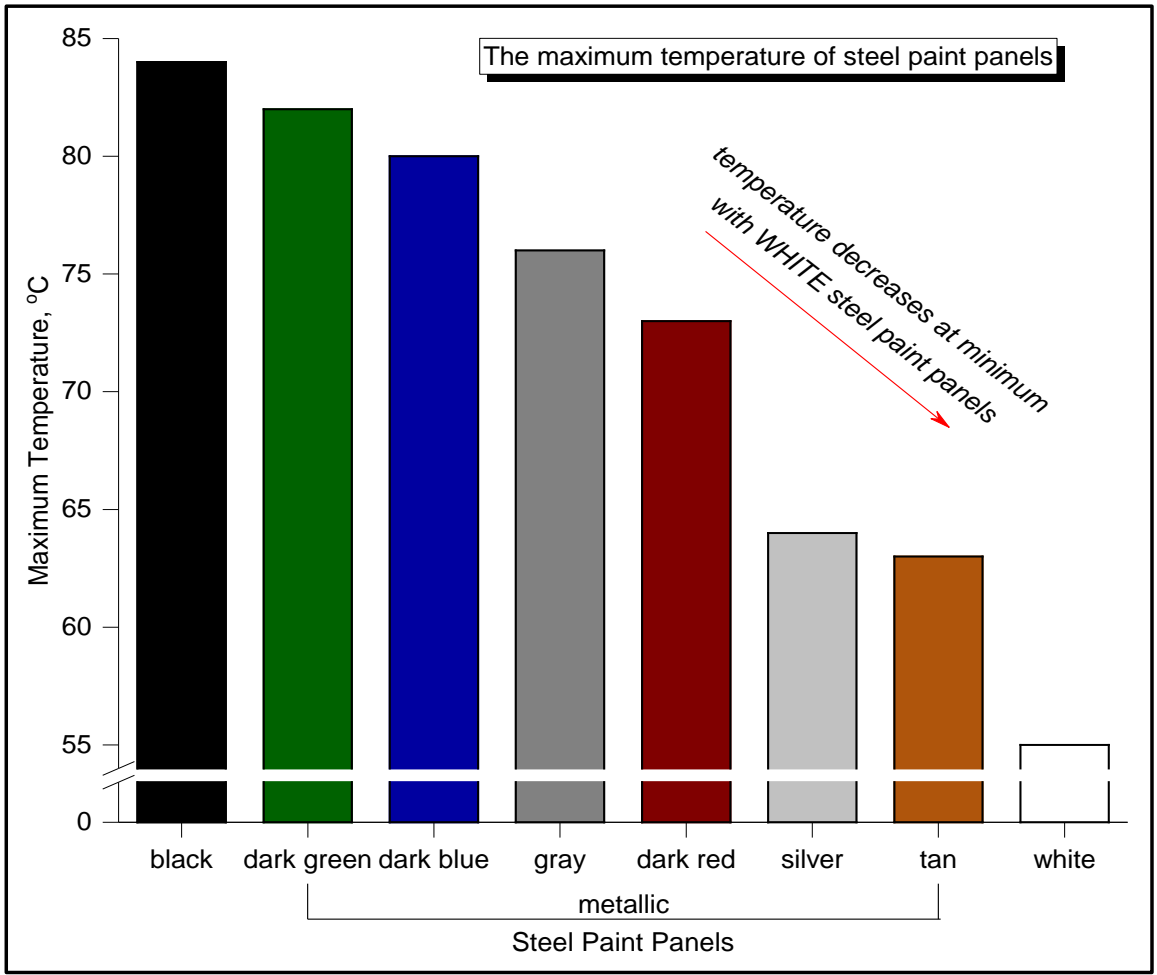

Figure 6. The maximum temperature of steel paint panels, adapted from [2].

colour-independent and that the action of temperature during the serving time may have less effect. It can still however be considered as an accelerated process as regards degradation of the clearcoat systems. Therefore, paint systems that are hotter will tend to be subjected to greater mechanical stresses than those that are exposed to lower temperature extremes, again favouring light colours over dark colours.

The surface roughness profile, indentation micro-hardness and scanning electronic microscopy (SEM) were used to assess the effect of the detergents on the appearance of the automotive clearcoat systems. Details of the surface roughness procedure have been reported elsewhere [9] [30] [31] [32] [33] [34], the microhardness procedure has likewise been reported elsewhere [28] [35], and similarly the SEM procedure has also been reported elsewhere [36] [37].

\section{Results and Discussion}

\subsection{Surface Roughness Evaluations}

In general, since the weather is incapable of repeating itself exactly, any outdoor exposure test is unique. The data were analysed using pair-sample $t$-Test, with 0.05 level of significance. For the house-use detergent, as shown in Figure 7, the surface roughness measurements obtained before the exposure (mean $=0.078$ $\mu \mathrm{m}, \pm \mathrm{SD}=0.011 \mu \mathrm{m}$ ) were lower than those which were achieved after exposure $($ mean $=0.108 \mu \mathrm{m}, \pm \mathrm{SD}=0.018 \mu \mathrm{m})(t(-6.6)=23, p=0.0001$. On the other hand, for the car wash detergent, the surface roughness measurements obtained before the exposure (mean $=0.083 \mu \mathrm{m}, \pm \mathrm{SD}=0.009 \mu \mathrm{m}$ ) were very close to 


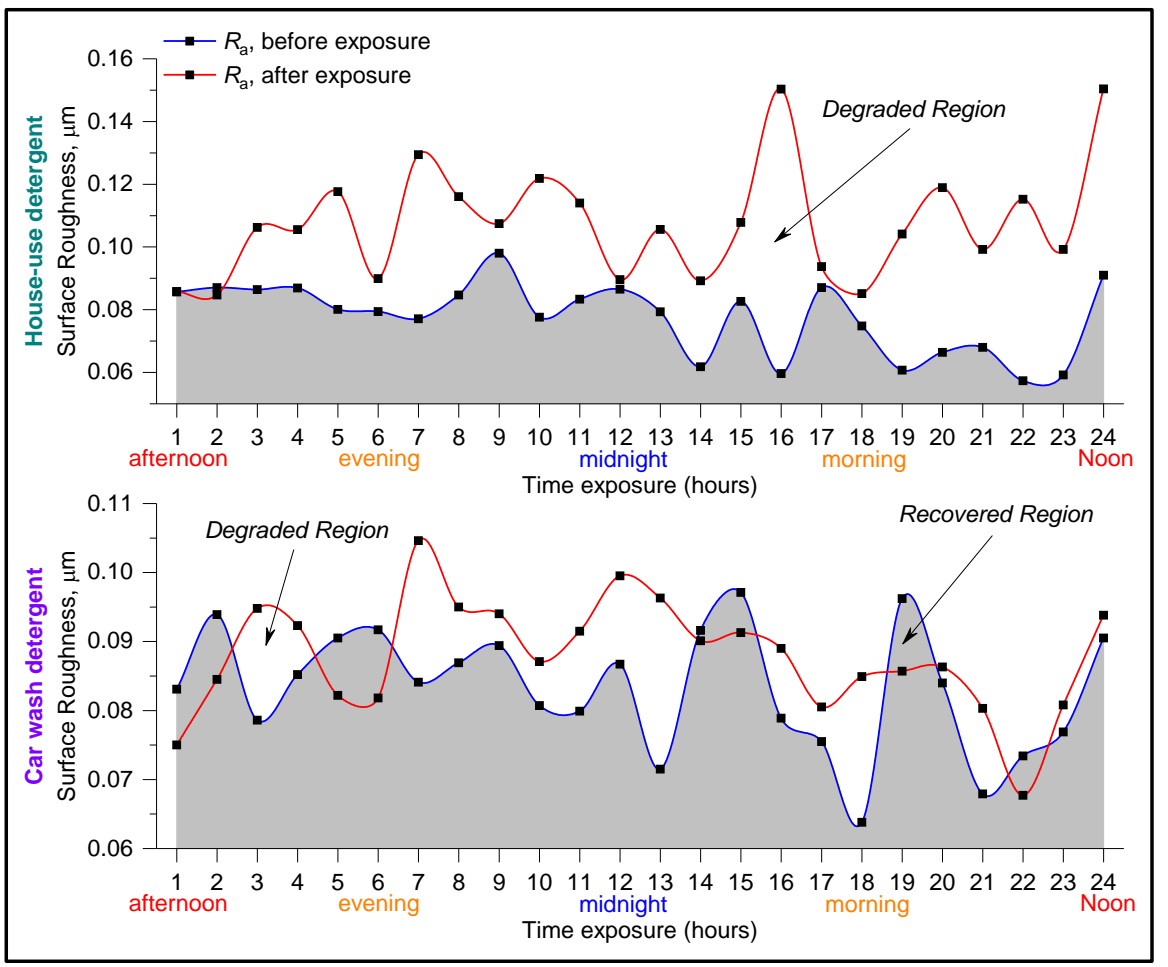

Figure 7. Repeatability performance of the surface roughness before and after exposure.

those which were obtained after exposure (mean $=0.088 \mu \mathrm{m}, \pm \mathrm{SD}=0.008 \mu \mathrm{m})$ $(t(-2.2)=23, p=0.0001$. The total net of degradation in the clearcoat level during the first 24 hours was $30.3 \mathrm{~nm}$ when using the house-use detergent, whereas it was $4.6 \mathrm{~nm}$ when using the car wash detergent. This may be attributed to the chemical influences of the house-use detergent being in contrast to the car wash detergent and causing the clearcoat surface to dissolve. Another reason for the greater value of the surface roughness in the clearcoat level can be the ascribed to the size of different peak-to-valley created by the process of painting on the production line. It can be seen clearly in the micro-hardness test that the weather is variable and thus materials exposed to it are in fact being exposed to a constantly changing environment (e.g., temperature, humidity, etc.).

\subsection{Micro-Hardness Evaluations}

In this section, Vicker's diamond under the load, $P$, was fixed at $300 \mathrm{~g}(2.942 \mathrm{~N})$ and the application time was kept at 15 seconds. Apparently, the weathering performance of the clearcoat indirectly reflected the mechanical performance of the micro-hardness. The data were analysed using a pair-sample $t$-Test, with 0.05 level of significance. For the house-use detergent, the micro-hardness measurements obtained before the exposure (mean $=16.629 \mathrm{HV}, \pm \mathrm{SD}=0.396$ $\mathrm{HV})$ were significantly lower than those which were achieved after exposure $($ mean $=17.988 \mathrm{HV}, \pm \mathrm{SD}=0.313 \mathrm{HV})(t(-14.8)=23, p=0.0001$. For the car wash detergent, the micro-hardness measurements obtained before the exposure (mean $=16.842 \mathrm{HV}, \pm \mathrm{SD}=0.588 \mathrm{HV}$ ) were significantly lower than those which were obtained after exposure $($ mean $=17.975 \mathrm{HV}, \pm \mathrm{SD}=0.450 \mathrm{HV})(t(-9.8)=$ 
$23, p=0.0001$. The total net of degradation in the clearcoat level during the first 24 hours was $1.358 \mathrm{HV}$ when using the house-use detergent whereas it was 1.133 $\mathrm{HV}$ when using the car wash detergent.

According to the micro-hardness tests, it can be concluded that the major degradation mechanism of the clearcoat system exposed to house-use detergent and car wash detergent is chemical rather than physical. Besides, weathering gives rise to non-uniform degradation of clearcoats which themselves contain composite structures with low and high crosslink density domains. Therefore, weathering may cause the development of local stresses in the clearcoat level, enlarge the pathway passages of water and result in a reduction in the barrier properties and an increase in water uptake, i.e., losses in corrosion resistance. Study of other properties of the clearcoat surface such as micro-hardness as measured by the Vickers micro-hardness test was sufficiently sensitive to aging by weathering as presented in Figure 8 , as the micro-hardness value of the clearcoat increased during the weathering cycle.

Figure 9 shows the variation of the Vickers indentation micro-hardness test for clearcoat automotive body with different detergents and loads $(10,25,50$, $100,200,300,500$ and $1000 \mathrm{~g}$ ) including a linear regression relationship of $R^{2}>$ 0.9. The holding time under various peak loads after completion of the indentation was 15 seconds. At small loads, the volume involved in the indentation (related to maximum indentation depth) corresponds to the individual grain size or splats which are composed of hard metal. In small volumes, the measurements are not influenced by pores or grain boundaries and the material properties well describe homogeneous material of single splats or grains. As the load increased, the micro-hardness value likewise increased. It seems that the load-dependent

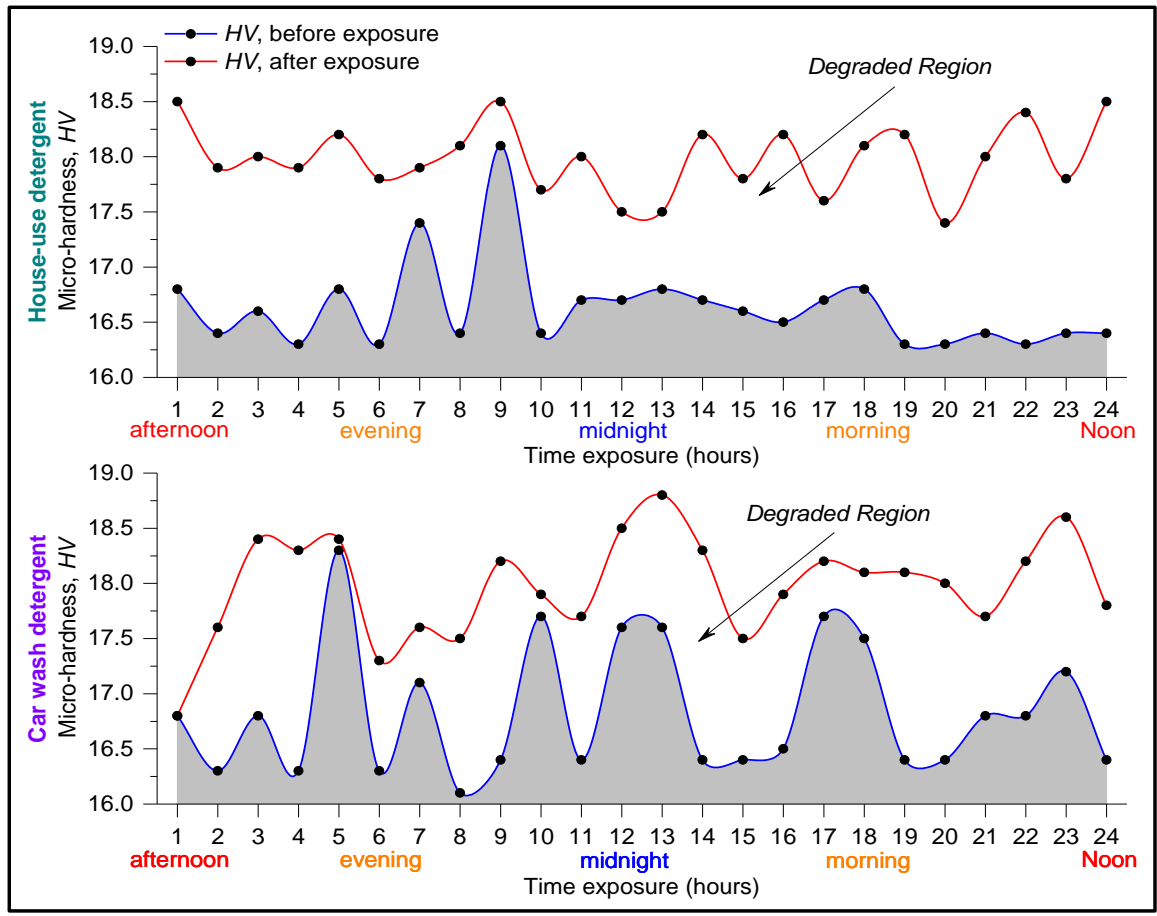

Figure 8. Repeatability performance of the micro-hardness before and after exposure. 


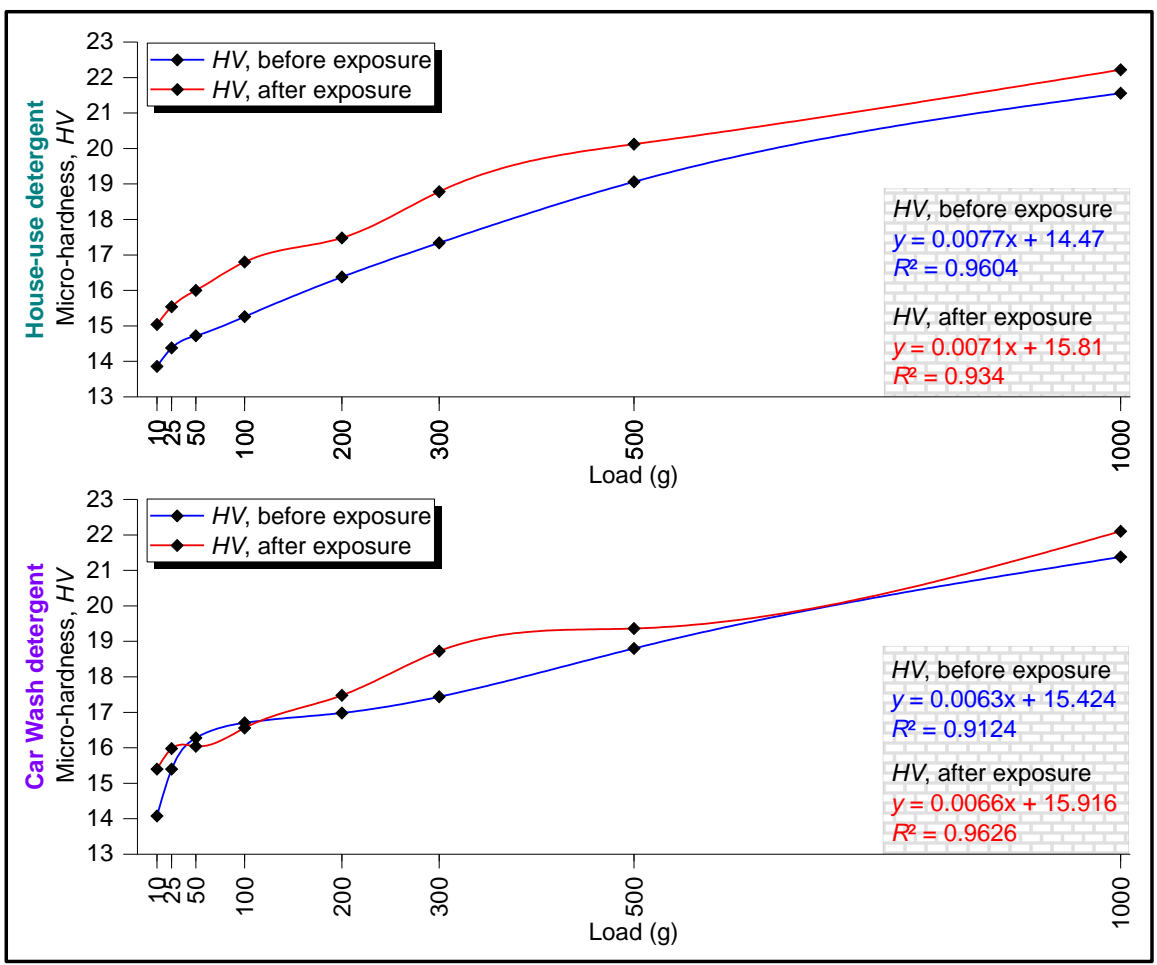

Figure 9. Load variation test of the clearcoat with different detergents.

with no crack or delamination occurring in the region dominated by the clearcoat level still exists. This is a natural behaviour, and is called reverse indentation size effect (RISE), in which plastic deformation is predominant. It can be concluded that the weathering test has various effects on the visco-elastic behaviour of the clearcoat system depending on the low or high exposure times.

The data were analysed using a pair-sample $t$-Test, with 0.05 level of significance. For the house-use detergent, the micro-hardness measurements obtained before the exposure (mean $=13.86 \mathrm{HV}, \pm \mathrm{SD}=0.553 \mathrm{HV}$ at $10 \mathrm{~g}$ ) until reach (mean $=21.56 \mathrm{HV}, \pm \mathrm{SD}=0.08 \mathrm{HV}$ at $1000 \mathrm{~g}$ ) were significantly lower than those which were obtained after exposure (mean $=15.04 \mathrm{HV}, \pm \mathrm{SD}=0.048 \mathrm{HV}$ at $10 \mathrm{~g})$ until reach $($ mean $=22.22 \mathrm{HV}, \pm \mathrm{SD}=0.193 \mathrm{HV}$ at $1000 \mathrm{~g})(t(-12.5)=7, p=$ 0.0001 . For the car wash detergent, the micro-hardness measurements obtained before the exposure (mean $=14.08 \mathrm{HV}, \pm \mathrm{SD}=0.132 \mathrm{HV}$ at $10 \mathrm{~g}$ ) until reach (mean $=21.38 \mathrm{HV}, \pm \mathrm{SD}=0.146 \mathrm{HV}$ at $1000 \mathrm{~g}$ ) were significantly lower than those which were obtained after exposure (mean $=15.4 \mathrm{HV}, \pm \mathrm{SD}=0.0632 \mathrm{HV}$ at $10 \mathrm{~g})$ until reach (mean $=22.1 \mathrm{HV}, \pm \mathrm{SD}=0.379 \mathrm{HV}$ at $1000 \mathrm{~g})(t(-2.9)=7, p=$ 0.0001

Table 1 shows Young's modulus values of clearcoat (CC) before and after exposure time with two different types of detergents. It is clearly noticeable that the $E$-values in the clearcoat system for the house-use detergent increased by $6.6 \%$ while those for the car wash detergent increased by $3.2 \%$. This indicated that for the same period, Young's modulus value increased double under the same conditions. The deviation for both detergents was almost the same, around $\pm 200 \mathrm{MPa}$. 
Table 1. Young's modulus values of clearcoat before and after exposure time with various detergent.

\begin{tabular}{ccccc}
\hline & \multicolumn{2}{c}{ House-use detergent } & \multicolumn{2}{c}{ Car wash detergent } \\
Young's & before exposure & after exposure & before exposure & after exposure \\
$\begin{array}{c}\text { Modulus, } \\
E,(\mathrm{MPa})\end{array}$ & time $($ mean $\pm \mathrm{SD})$ & time (mean $\pm \mathrm{SD})$ & time $($ mean $\pm \mathrm{SD})$ & time (mean $\pm \mathrm{SD})$ \\
& $1613.9 \pm 257.7$ & $1728.6 \pm 241.2$ & $1668.7 \pm 215.2$ & $1724.6 \pm 219.4$ \\
\hline
\end{tabular}

The results of the 4-week outdoor exposure are presented in Figure 10 and Figure 11. It is clearly shown that increases in the weathering exposure time up to 672 hours cause significant increases in the maximum durable loads for both (house-use detergent and car wash detergent) on the clearcoat systems. Cyclic variation of temperature induces alternate volume expansion and contraction, which causes non-uniform stress such as water absorption that can also lead to fatigue and loss of physical properties. The combination of relative humidity and temperature cycles can also cause severe deterioration in the form of surface cracks in the clearcoat structure.

Sunlight reaching the earth's surface contains a broad range of wavelengths from 280 to $1400 \mathrm{~nm}$. The worst aspect is the ultraviolet (UV) which is in the range of $<380 \mathrm{~nm}$. Most polymer materials are very sensitive to this aspect of the sunlight. For instance, polyesters and alkyds have absorption peaks of around 315 and $280-310 \mathrm{~nm}$, respectively [38]. The absorbed energy can cause photodegradation the mechanism of which is well known and has been widely discussed in the literature review [38] [39]. Car washing, dew formation, and rain are conditions by which the water is in direct contact with automotive coating layers during a car's service life. Although most polymer materials are hydrophobic and thus not affected by water and relative humidity, some that have $\mathrm{pH}$-sensitive chemical linkages in their structure can be hydrolysed by relative humidity or water. Acrylic/Melamine as the typical structure used in automotive clearcoats is vulnerable to water and highly susceptible to degrade hydrolytically and yet another is the diverse class of organic coatings [40].

In Figure 10, for the house-use detergent, the surface roughness measurements obtained before the exposure (mean $=0.075 \mu \mathrm{m}, \pm \mathrm{SD}=0.011 \mu \mathrm{m}$ ) were lower than those which were obtained after exposure (mean $=0.089 \mu \mathrm{m}, \pm \mathrm{SD}=$ $0.009 \mu \mathrm{m})$. On the other hand, for the car wash detergent, the surface roughness measurements obtained before the exposure (mean $=0.079 \mu \mathrm{m}, \pm \mathrm{SD}=0.007$ $\mu \mathrm{m}$ ) were very close to those which were obtained after exposure (mean $=0.086$ $\mu \mathrm{m}, \pm \mathrm{SD}=0.007 \mu \mathrm{m})$. The total net of degradation in the clearcoat level was $R_{\mathrm{a}}$ $=0.014 \mu \mathrm{m}$ when using the house-use detergent whereas it was $R_{\mathrm{a}}=0.007 \mu \mathrm{m}$ when using the car wash detergent.

In Figure 11, for the house-use detergent, the micro-hardness measurements obtained before the exposure (mean $=16.525 \mathrm{HV}, \pm \mathrm{SD}=0.043 \mathrm{HV}$ ) were significantly lower than those which were achieved after exposure (mean $=18.350$ $\mathrm{HV}, \pm \mathrm{SD}=0.112 \mathrm{HV}$ ). For the car wash detergent, the micro-hardness 


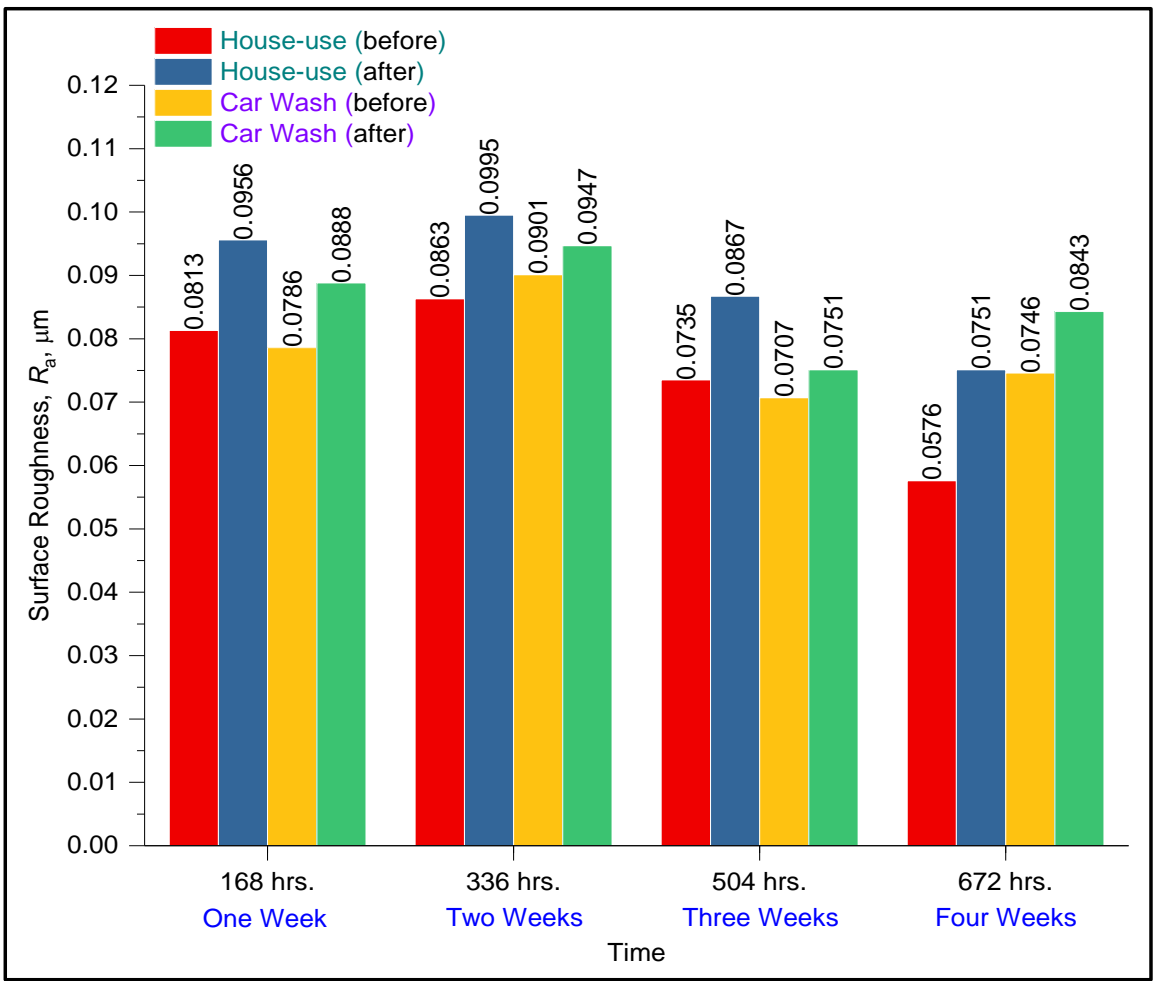

Figure 10. Time variation of the surface roughness test for clearcoat with different detergents.

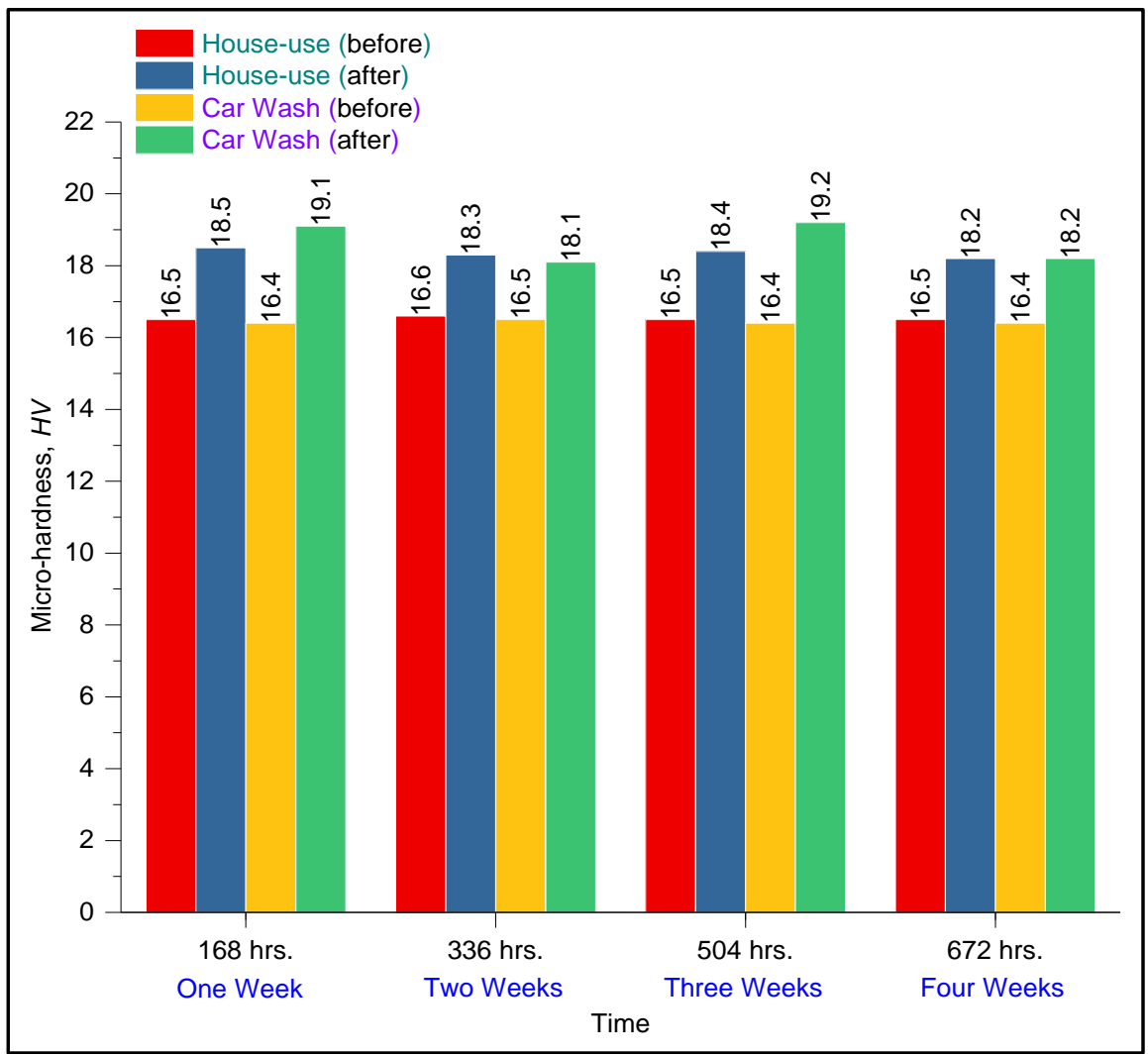

Figure 11. Time variation of the micro-hardness test for clearcoat with various detergents. 
measurements obtained before the exposure (mean $=16.425 \mathrm{HV}, \pm \mathrm{SD}=0.043$ $\mathrm{HV}$ ) were significantly lower than those which were achieved after exposure (mean $=18.650 \mathrm{HV}, \pm \mathrm{SD}=0.502 \mathrm{HV})$. The total net of degradation in the clearcoat level was $1.825 \mathrm{HV}$ when using the house-use detergent whereas it was $2.225 \mathrm{HV}$ when using the car wash detergent. So, the micro-hardness value of the clearcoat system increased dramatically during the weathering cycle.

\subsection{Surface Morphology Evaluation}

To investigate the surface morphology of the clearcoat system during the weathering cycle, scanning electronic microscopy (SEM) was used. Figure 12 shows the surface morphology of the clearcoat samples after various exposure times and different detergents (house-use and car wash) with low and high magnification. As can be seen, weathered surfaces of both clearcoats indicated that increased times of weathering exposure up to 672 hours lead to behaviours which are not the same for the clearcoat system with a house-use detergent and a car wash detergent, especially at initial times of exposure. At the early stage of exposure, the clearcoat is relatively uniform and it loses its uniformity as the weathering time elapses. The longer exposure proceeds, the rougher the surface becomes and it also becomes enriched with the pigment. In general, both clearcoats exhibit an almost smooth surface, while after exposure time with the house-use detergent, the surface profile becomes rougher. The produced fracture scratches on the clearcoat with house-use detergent are deeper, have sharper edges and seem much harsher than with the other detergent. It also shows that the surface has a non-uniform porous morphology. With car wash detergent, this led to a more plastic type damage with smoother surface giving lowered light scattering and hence improving the appearance of the body of the car.

In the meantime, nano-scale voids and micro-cracks designated by the solid yellow arrows to guide the eye are found in Figure 12. These nano-scale voids and micro-cracks could cause the modification of the stress and strain during plastic deformation. The micro-cracks can affect the stress states which are around the cracks by releasing elastic stress. Also, the existence of the microcracks can lead to increasing the number of dislocations at the grain boundaries and result in the effect of back stress on the plastic deformation in the ultra fine grained phase that is relevant to dynamic strain hardening.

Therefore, the SEM electronic micrographic analysis confirms the results of surface roughness, $R_{\mathrm{a}}$, and indentation micro-hardness. The clearcoat system with house-use detergent shows the highest surface roughness and micro-hardness values.

\section{Concluding Remarks}

This paper presents studies on the repeatability performance of the clearcoat layer of an automotive exposed to the impact of outside experimental factors depending on the exposure time along with two different detergents (house-use and car wash). The general conclusions obtained are shown below: 


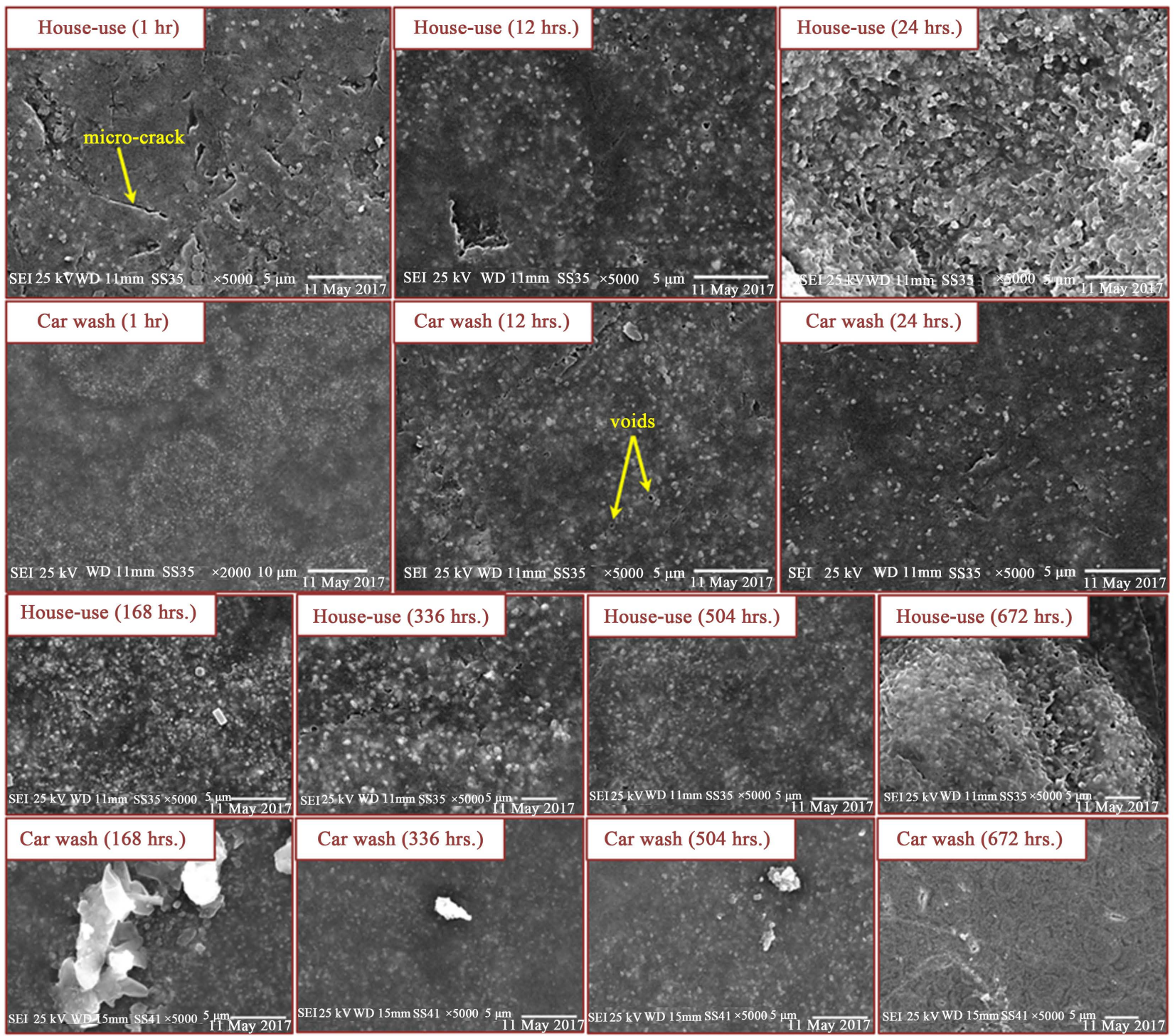

Figure 12. Time variation of the micro-hardness test for clearcoat with various detergents.

1) For the surface roughness, the total net of degradation in the clearcoat level during the first 24 hours was $30.3 \mathrm{~nm}$ when using the house-use detergent whereas it was $4.6 \mathrm{~nm}$ when using the car wash detergent.

2) For the micro-hardness, the total net of degradation in the clearcoat level during the first 24 hours was $1.358 \mathrm{HV}$ when using the house-use detergent whereas it was $1.133 \mathrm{HV}$ when using the car wash detergent.

3) The total net of degradation after 4-week outdoor exposure was $0.014 \mu \mathrm{m}$ for $R_{\mathrm{a}}$ when using the house-use detergent whereas it was $0.007 \mu \mathrm{m}$ when using the car wash detergent.

4) The total net of degradation after 4-week outdoor exposure was $1.825 \mathrm{HV}$ for micro-hardness when using the house-use detergent whereas it was $2.225 \mathrm{HV}$ when using the car wash detergent.

In conclusion, car wash detergent indicated lower values of both $R_{\mathrm{a}}$ and HV after the various times of weathering exposure, whereas house-use detergent in- 
dicated otherwise.

\section{Conflicts of Interest}

The authors have no conflicts of interest.

\section{Funding}

The authors received no financial support for the research and/or for the publication of this article.

\section{References}

[1] Bewilogua, K., Bräuer, G., Dietz, A., Gäbler, J., Goch, G., Karpuschewski, B. and Szyszka, B. (2009) Surface Technology for Automotive Engineering. CIRP AnnalsManufacturing Technology, 58, 608-627. https://doi.org/10.1016/j.cirp.2009.09.001

[2] Nichols, M.E. (2012) 20-Paint Weathering Tests. In: Kutz, M., Ed., Handbook of Environmental Degradation of Materials, 2nd Edition, William Andrew Publishing, Oxford, 597-619. https://doi.org/10.1016/B978-1-4377-3455-3.00020-1

[3] Tahmassebi, N., Moradian, S., Ramezanzadeh, B., Khosravi, A. and Behdad, S. (2010) Effect of Addition of Hydrophobic Nano Silica on Viscoelastic Properties and Scratch Resistance of an Acrylic/Melamine Automotive Clearcoat. Tribology International, 43, 685-693. https://doi.org/10.1016/j.triboint.2009.10.008

[4] Yari, H., Mohseni, M., Ramezanzadeh, B. and Mohammad Rabea, A. (2012) Investigating the Degradation Resistance of Silicone-Acrylate Containing Automotive Clearcoats Exposed to Bird Droppings. Progress in Organic Coatings, 75, 170-177. https://doi.org/10.1016/j.porgcoat.2012.04.014

[5] Domnick, J., Gruseck, D., Pulli, K., Scheibe, A., Ye, Q. and Brinckmann, F. (2011) Investigations of the Drying Process of a Water Based Paint Film for Automotive Applications. Chemical Engineering and Processing. Process Intensification, 50, 495-502. https://doi.org/10.1016/j.cep.2010.08.021

[6] Gerlock, J.L., Prater, T.J., Kaberline, S.L. and deVries, J.E. (1995) Assessment of Photooxidation in Multi-Layer Coating Systems by Time-of-Flight Secondary Ion Mass Spectrometry. Polymer Degradation and Stability, 47, 405-411. https://doi.org/10.1016/0141-3910(95)00007-0

[7] Razin, A.A., Yari, H. and Ramezanzadeh, B. (2015) Stone-Chipping and Adhesion Deterioration of Automotive Coating Systems Caused by Outdoor Weathering of Underneath Layers. Journal of Industrial and Engineering Chemistry, 31, 291-300. https://doi.org/10.1016/j.jiec.2015.07.001

[8] Hainsworth, S.V. and Kilgallon, P.J. (2008) Temperature-Variant Scratch Deformation Response of Automotive Paint Systems. Progress in Organic Coatings, 62, 21 27. https://doi.org/10.1016/j.porgcoat.2007.09.006

[9] Alsoufi, M.S. and Bawazeer, T.M. (2015) The Effect of Aggressive Biological Materials on a Painted Automotive Body Surface Roughness. American Journal of Nano Research and Applications, 3, 17-26.

[10] Nichols, M.E. and Darr, C.A. (1998) Effect of Weathering on the Stress Distribution and Mechanical Performance of Automotive Paint Systems. Journal of Coatings Technology, 70, 141-149. https://doi.org/10.1007/BF02730084

[11] Nichols, M.E., et al. (1999) The Effects of Weathering on the Mechanical Performance of Automotive Paint Systems. Progress in Organic Coatings, 35, 153-159. https://doi.org/10.1016/S0300-9440(98)00060-5 
[12] Bauer, D.R. (1982) Degradation of Organic Coatings. I. Hydrolysis of Melamine Formaldehyde/Acrylic Copolymer Films. Journal of Applied Polymer Science, 27, 3651-3662. https://doi.org/10.1002/app.1982.070271002

[13] Ramezanzadeh, B., Mohseni, M. and Naseh, N. (2014) Effects of Different Silicon-Based Surface Active Additives on Degradability of Clearcoats Exposed to Bird Droppings. Journal of Coatings Technology and Research, 11, 533-543. https://doi.org/10.1007/s11998-014-9572-0

[14] Ramezanzadeh, B., Mohseni, M. and Yari, H. (2010) The Effect of Natural Tree Gum and Environmental Condition on the Degradation of a Typical Automotive Clear Coat. Journal of Polymers and the Environment, 18, 545-557. https://doi.org/10.1007/s10924-010-0201-4

[15] Ramezanzadeh, B., Mohseni, M. and Yari, H. (2010) The Role of Basecoat Pigmentation on the Biological Resistance of an Automotive Clearcoat. Journal of Coatings Technology and Research, 7, 677-689. https://doi.org/10.1007/s11998-010-9254-5

[16] Nguyen, T., Martin, J. and Byrd, E. (2003) Relating Laboratory and Outdoor Exposure of Coatings: IV. Mode and Mechanism for Hydrolytic Degradation of AcrylicMelamine Coatings Exposed to Water Vapor in the Absence of UV Light. Journal of Coatings Technology, 75, 37-50. https://doi.org/10.1007/BF02720521

[17] Martin, J.W., et al. (2002) Relating Laboratory and Outdoor Exposures of Acrylic Melamine Coatings: I. Cumulative Damage Model and Laboratory Exposure Apparatus. Polymer Degradation and Stability, 75, 193-210. https://doi.org/10.1016/S0141-3910(01)00218-X

[18] Nguyen, T., et al. (2002) Relating Laboratory and Outdoor Exposure of Coatings: II. Journal of Coatings Technology, 74, 65-80. https://doi.org/10.1007/BF02697976

[19] Gerlock, J.L., et al. (1986) Formaldehyde Release from Acrylic/Melamine Coatings during Photolysis and the Mechanism of Photoenhanced Cross-Link Hydrolysis. Industrial \& Engineering Chemistry Product Research and Development, 25, 449453. https://doi.org/10.1021/i300023a014

[20] Yari, H., et al. (2009) The Effect of Basecoat Pigmentation on Mechanical Properties of an Automotive Basecoat/Clearcoat System during Weathering. Polymer Degradation and Stability, 94, 1281-1289. https://doi.org/10.1016/j.polymdegradstab.2009.04.008

[21] Osterhold, M. and Glöckner, P. (2001) Influence of Weathering on Physical Properties of Clearcoats. Progress in Organic Coatings, 41, 177-182. https://doi.org/10.1016/S0300-9440(01)00152-7

[22] Tahmassebi, N. and Moradian, S. (2004) Predicting the Performances of Basecoat/Clearcoat Automotive Paint Systems by the Use of Adhesion, Scratch and Mar Resistance Measurements. Polymer Degradation and Stability, 83, 405-410. https://doi.org/10.1016/j.polymdegradstab.2003.09.002

[23] Gregorovich, B.V., Adamsons, K. and Lin, L. (2001) Scratch and Mar and Other Mechanical Properties as a Function of Chemical Structure for Automotive Refinish Coatings. Progress in Organic Coatings, 43, 175-187. https://doi.org/10.1016/S0300-9440(01)00187-4

[24] Nichols, M.E. (2002) Anticipating Paint Cracking: The Application of Fracture Mechanics to the Study of Paint Weathering. Journal of Coatings Technology, 74, 39-46. https://doi.org/10.1007/BF02720138

[25] Skaja, A., Fernando, D. and Croll, S. (2006) Mechanical Property Changes and Degradation during Accelerated Weathering of Polyester-Urethane Coatings. Journal of Coatings Technology and Research, 3, 1-51.

https://doi.org/10.1007/s11998-006-0004-7 
[26] Tahmassebi, N., Moradian, S. and Mirabedini, S.M. (2005) Evaluation of the Weathering Performance of Basecoat/Clearcoat Automotive Paint Systems by Electrochemical Properties Measurements. Progress in Organic Coatings, 54, 384-389. https://doi.org/10.1016/j.porgcoat.2005.08.004

[27] Ramezanzadeh, B., et al. (2009) An Evaluation of an Automotive Clear Coat Performance Exposed to Bird Droppings under Different Testing Approaches. Progress in Organic Coatings, 66, 149-160. https://doi.org/10.1016/j.porgcoat.2009.06.010

[28] Alsoufi, M.S., et al. (2016) Experimental Study of Surface Roughness and Micro-Hardness Obtained by Cutting Carbon Steel with Abrasive Water Jet and Laser Beam Technologies. American Journal of Mechanical Engineering, 4, 173-181.

[29] Alsoufi, M.S. (2017) State-of-the-Art in Abrasive Water Jet Cutting Technology and the Promise for Micro- and Nano-Machining. International Journal of Mechanical Engineering and Applications, 5, 1-14. https://doi.org/10.11648/j.ijmea.20170501.11

[30] Bawazeer, T.M., et al. (2016) Effect of Aqueous Extracts of Salvadora Persica "Miswak" on the Acid Eroded Enamel Surface at Nano-Mechanical Scale. Materials Sciences and Applications, 7, 754-771. https://doi.org/10.4236/msa.2016.711059

[31] Alsoufi, M.S. and Bawazeer, T.M. (2015) Quantifying Assessment of Touch-Feel Perception: An Investigation Using Stylus Base Equipment and Self-Touch (Human Fingertip). Umm Al-Qura University: Journal of Engineering and Architecture, 1, $1-16$.

[32] Suker, D.K., et al. (2016) Studying the Effect of Cutting Conditions in Turning Process on Surface Roughness for Different Materials. World Journal of Research and Review, 2, 6-21.

[33] Alsoufi, M.S., et al. (2017) Abrasive Water Jet Machining of Thick Carrara Marble: Cutting Performance vs. Profile, Lagging and Water Jet Angle Assessments. Materials Sciences and Applications, 8, 361-375. https://doi.org/10.4236/msa.2017.85025

[34] Alsoufi, M.S., et al. (2017) Influence of Abrasive Water Jet Machining Parameters on the Surface Texture Quality of Carrara Marble. Journal of Surface Engineered Materials and Advanced Technology, 7, 25-37. https://doi.org/10.4236/jsemat.2017.72003

[35] Alsoufi, M.S., et al. (2016) Surface Roughness and Knoop Indentation Micro-Hardness Behavior of Aluminium Oxide $\left(\mathrm{Al}_{2} \mathrm{O}_{3}\right)$ and Polystyrene $\left(\mathrm{C}_{8} \mathrm{H}_{8}\right)_{n}$ Materials. International Journal of Mechanical \& Mechatronics Engineering, 16, 43-49.

[36] Alsoufi, M.S. (2016) Tactile Perception of Passenger Vehicle Interior Polymer Surfaces: An Investigation Using Fingertip Blind Observations and Friction Properties. International Journal of Science and Research, 5, 1447-1454.

[37] Bawazeer, T.M. and Alsoufi, M.S. (2017) Surface Characterization and Properties of Raw and Degummed (Bombyx mori) Silk Fibroin Fiber toward High Performance Applications of "Kisswa Al-Kabba". International Journal of Current Research, 9, 48335-48343.

[38] Valet, A. (1997) Light Stabilizers for Paints (Coating Technology). Vincentz Network, Hannover, 144.

[39] Pospíšil, J. and Nešpurek, S. (2000) Photostabilization of Coatings. Mechanisms and Performance. Progress in Polymer Science, 25, 1261-1335. https://doi.org/10.1016/S0079-6700(00)00029-0

[40] Mohseni, M., Ramezanzadeh, B. and Yari, H. (2011) Effects of Environmental Conditions on Degradation of Automotive Coatings, New Trends and Developments in Automotive Industry. InTech Publisher, Croatia, 394. 
Submit or recommend next manuscript to SCIRP and we will provide best service for you:

Accepting pre-submission inquiries through Email, Facebook, LinkedIn, Twitter, etc. A wide selection of journals (inclusive of 9 subjects, more than 200 journals)

Providing 24-hour high-quality service

User-friendly online submission system

Fair and swift peer-review system

Efficient typesetting and proofreading procedure

Display of the result of downloads and visits, as well as the number of cited articles Maximum dissemination of your research work

Submit your manuscript at: http://papersubmission.scirp.org/

Or contact msa@scirp.org 